\title{
Editorial
}

\section{Planning for a new IUAPPA World Congress}

Planning for a new World Congress - as we now are is an occasion when we should stand back, and try to identify the 'big questions', the underlying pressures and challenges which should be shaping the progress of atmospheric science and policy.

Of course, you never quite succeed. One half-decent excuse for failure is that World Congresses are circular, iterative processes: you choose the theme, but then the submitted papers, in their variety and detail, tell you what is really happening, and what we should have had the sense to see three years earlier.

It is only a half-decent excuse because even circular and iterative processes have to start somewhere. So to promote debate among NACA members, and the wider membership of IUAPPA, let me offer some suggestions:

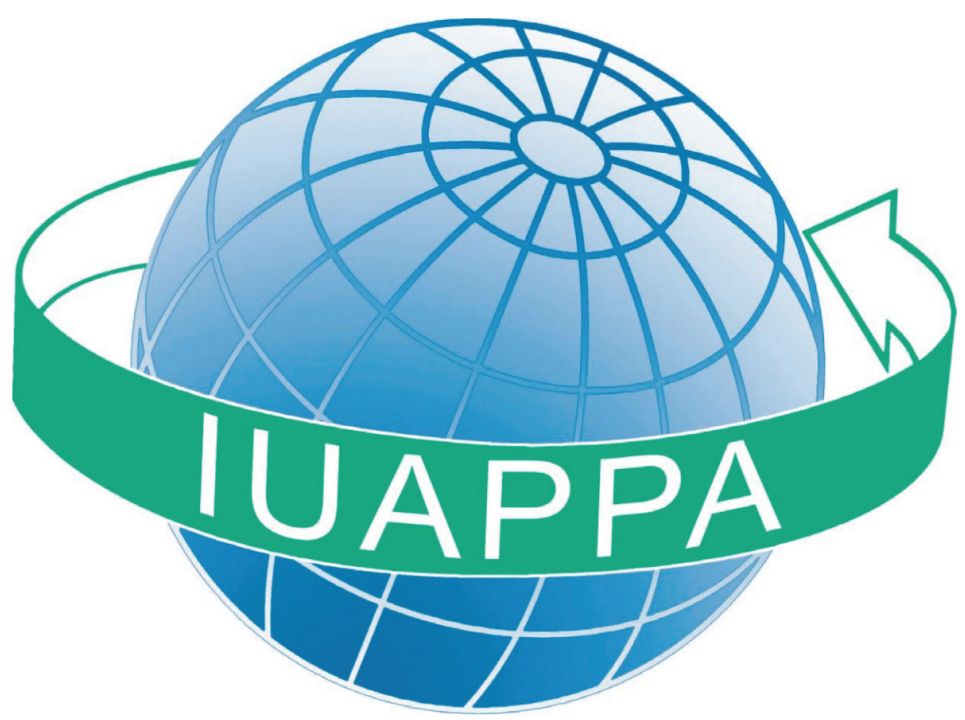

First, a suggestion for countries in the 'developed' world. Here there are signs that progress in air pollution control may be stalling. Some of our core policies - and new technologies - appear not to be delivering the improvements that were forecast. Maybe this just reflects the difficulty of creating 'real-world' conditions to test new technologies and policies. Maybe this is an illusion created by the increasing evidence that health effects of air pollution - not just PM and Ozone, but now also $\mathrm{NO}_{2}$ - are far more severe than we thought, increasing the gulf between what we are doing and what needs to be done. We need to know. And then we may need to think hard about how to restart the engines of progress in a world potentially mired by deficits and recessions for some years ahead.

For the rapidly expanding mega-cities of the developing world, a simpler but starker question: how can we realistically fashion air quality strategies capable of effective implementation in circumstances of rapid migration and population movement, informal settlements, poverty and unstable governance?

Finally, a question uniting the two. How do we ensure social equity in atmospheric policy? Air quality policies are primarily for those poorer area which bear the brunt of pollution. Unwittingly however, they usually also bear the brunt of the cost - as when we ban the old and polluting vehicles that may in practice provide almost the only possibility for the poor to find work or get to health centres. Of course we can leave these difficult questions to politicians: it is part of their job to decide who should bear costs. But it is for the scientists and the policy analysts to better identify and assess the costs, where they fall, and what are the alternatives.

So three possibilities, for starters. South Africa, with its unique experience and diversity, is well placed to suggest others.

\section{Sir Richard Mills}

Director, IUAPPA 